\title{
Asceticism as Activism: Effective Altruism's Neglected Other Half
}

\begin{abstract}
What I seek to do in this paper is to reemphasize what I see as the forgotten or neglected other half of the effective altruist equation. Effective altruists need to take seriously the ways in which their actions contribute to systemic inequality and structural violence. Charitable donation is not enough to create a paradigm shift or stop systemic injustice. In tackling systemic injustice, the ascetic response may allow effective altruists to attack the roots of the problem more directly. Further, the cost-benefit analysis and randomized controlled trials favored by the movement can produce distinctly biased perceptions that leave effective altruists blind to the political dimensions of many types of harm. Balancing ascetic approaches to combating suffering may temper the overzealous focus on cost-effective charities and make room for the support of the causes this narrow focus excludes. Ultimately, this paper defends the basic tenets of effective altruism: that the capable have a duty to reduce suffering in the world and that we should apply our powers of reason in order to make our labors maximally effective.
\end{abstract}

\section{Introduction}

Effective altruism (EA) is characterised by several key premises. First and foremost is the idea that we ought to make the world a better place and that we should apply our powers of reason to the efforts we make in that regard in order to make them maximally effective. People living in the Global North often have more money than needed to sustain themselves. Because of the current economic dynamics of the world, this means even small donations of what amounts to spare change can have significant effects on the lives of impoverished people in the Global South. These facts have led effective altruists to focus their attention on making donations to charities that have been evaluated for cost-effectiveness and which target the world's poorest people. For this reason, EA has a unique relationship to money and economics. This relationship produces a distinct skew in the way effective altruists approach the issues they target, and not always for the better. In particular, the idea of earning to give has gained some popularity, leading some to seek high earning careers with little concern for the ethical impact of the nature of these careers in themselves.

Much of what I argue for in this paper is not revolutionary or unique. In fact, asceticism is old news, so to speak, as can be seen in the longstanding practice of fasting and other forms of austerity in many of the world's oldest faiths. Yet, in light of all the energy around EA as a young movement 
and the excitement, it has generated about charitable giving, these points seem worth mentioning afresh. Thus, what I seek to do in this paper is to reemphasise what I see as the forgotten or neglected other half of the effective altruist equation: namely, the role of self-denial and restraint. Effective altruists need to take seriously how their actions contribute to systemic inequality and structural violence. Donation is not enough to create a paradigm shift or to stop systemic injustice. In addition to considering costs and benefits as they relate to charitable donations, effective altruists should be mindful consumers and mobilise their inaction for good effects as well. In order to maximise our positive influence on the world, we must mobilise not only our activist instincts but also our ascetic ones. We must be able to recognise not only the types of actions that can best effect positive change, but also the types of inaction that can stall or reverse the root causes of suffering. Considering both our actions and inactions as representing equal opportunity for effecting change in the world gives us a more well-rounded picture of the moral landscape. This positions my article in favour of EA's core premises, but against the sub-trend of earning to give. Ultimately, the point I hope to make is that the reinvigoration of interest in charitable giving spurred on by effective altruist's stands only to be enhanced if it is partnered with some of the wisdom and moderation of the much more ancient notion of asceticism.

To make my case, I will develop my line of argument in the following manner: I will start by going over some worries about giving (section 2), and then I will introduce and defend ascetic forms of activism, explaining how these methods can avoid or mitigate some of the worries connected with donation (section 3), next, I will develop this into my objections against earning to give (section 4), and finally I will answer a common worry about asceticism and EA more generally, namely the concern about "overdemandingness" (section 5). ${ }^{1}$

1 It is worth noting that the effective altruist movement has evolved since the writing of the initial version of this paper, which was published in 2017 in Essays in Philosophy. Since that time, EA has been explicit that it is not solely focused on donations or synonymous with "earning to give," see Todd, "Misconceptions About Effective Altruism.” Still, recognition or open embrace of the ascetic side of the equation I advocate for here has yet to emerge. 


\section{Systemic Injustice and the Question of the Efficacy of Aid}

Given the resources and wealth people in the developed countries of the Global North often enjoy, this entails a distinct burden to use this privilege for good. Similar to the idea that a doctor has special duties to help the sick because he or she has more knowledge and ability to help than a layperson, so we logically have a duty to give some of our wealth away to others who do not have it, when doing so would not present a significant burden to ourselves and would significantly improve the lives of those to whom we give. If the motivating force behind giving is not the "warm glow," 2 as Peter Singer has been known to put it, but the chance to materially reduce suffering in the world, it seems only logical that we should be attentive to the effectiveness of our donations.

Attending to this effectiveness, however, can be a steeper challenge than it initially seems. As Andrew Kuper points out in his article, "More Than Charity," "nothing in the principle of aid or charity determines that the right action in any or all contexts is donation"3. To truly be effective in our altruism, we need to be able to recognise situations in which charitable giving is not the right answer, and where it may in fact cause harm. As Keith Horton notes in his article "Aid Agencies: The Epistemic Question," "Many contributors to this debate have apparently taken it that one may simply assume that the effects of the work such agencies do are overwhelmingly positive ... however, one finds a number of concerns about such agencies and the work they do that put that assumption in serious doubt." 4

Emily Clough takes the argument one step further in her article, "Effective Altruism's Political Blind Spot," in the Boston Review. Efficacy in aid is particularly thorny and difficult to determine. Not only is it difficult to get good data, but even the darling methods of randomised control trials (RCTs) that effective altruist organisations like GiveWell and Giving What We Can use produce distinctly skewed results. ${ }^{5}$ She says,

"While they are good at measuring the proximate effects of a program on its immediate target subjects, RCTs are bad at detecting any unintended effects of a program, especially those effects that fall outside the population or timeframe that the organisation or researchers had in mind. For example, an RCT might determine whether a bed net distribution program lowered the incidence of malaria among

2 Singer, Most Good, 5.

3 Kuper, "More Than Charity," 113.

4 Horton, "Aid Agencies: The Epistemic Question," 29.

5 Clough, "Effective Altruism's Political Blind Spot." 
its target population. But it would be less likely to capture whether the program unintentionally demobilised political pressures on the government to build a more effective malaria eradication program, one that would ultimately affect more people. RCTs thus potentially miss broader insights and side effects of a program beyond its target population."

The critical point here is that a political dimension to poverty is ignored in the standard process effective altruists use to target their giving. Given this blind spot, the aid that effective altruists provide risks actually worsening some systemic problems, as Clough goes on to describe:

"In the worst case, the presence of NGOs induces exit from the state sector. When relatively efficient, well-functioning NGOs enter a health or education market, for example, citizens in that market who are paying attention are likely to switch from government services to NGO services. The result is a disengagement of the most mobilised, discerning poor citizens from the state. These are the citizens most likely to have played a previous role in monitoring the quality of state services and advocating for improvements. Once they exit, the pressure on the government to maintain and improve services eases, and the quality of government provision is likely to fall." 7

Iason Gabriel, in his article "Effective Altruism and its Critics," describes yet another scenario where EA's cost-effectiveness analysis can fall short. $\mathrm{He}$ recounts a hypothetical situation where a charity has the option to build a water sanitation system using either outside labour or members of the recipient community to construct it. ${ }^{8}$ Since they are professionals, the outside labourers will surely build a better system that will be less likely to need repair in the near future, making them the more cost-effective investment. ${ }^{9}$ However, as Gabriel points out, this leaves no room in the calculus for the community's emotional investment in the project if allowed to build the system themselves. ${ }^{10}$ He says, "we might believe that it is valuable for people to choose the path their community takes and to participate in realising these goals, for reasons of autonomy and self-esteem. After all, there is an important moral difference between receiving something as a gift and bringing it into existence through one's effort." 11

6 Ibid.

7 Ibid.

8 Gabriel, "Effective Altruism and its Critics," 9.

9 Ibid.

10 Ibid.

11 Ibid. 
Steven G. Brown adds to the discussion in his article, "Supporting the Best Charities is Harder than it Seems," wherein he describes how GiveWell's methodology leads them to "to rule out effective organisations that would do great work with further funding." 12 Specifically, he argues,

"GiveWell's methodology prioritises easily measurable metrics, and those outcomes that can also be researched and tracked in a particularly rigorous way. This leads to their most serious drawback: overlooking projects that should be a high priority, but are difficult to measure. When one takes a step back and asks what it would take to better a place that is not doing well, one will surely come across many difficult to measure answers. For example, it is striking that since it began giving ratings in 2008, GiveWell has only recommended a single international educational charity. Pratham is an organisation that runs an innovative and extraordinarily successful reading program called Read India that trains community volunteers to be teachers in villages all across the country. Citing difficulties in measuring the effectiveness of educational projects, GiveWell stopped recommending Pratham in 2011, and has never recommended another educational charity since. This is despite the fact that education is certainly one of the most important things a community must have if it is to rise out of poverty and not merely survive." 13

Clearly, the narrow approach effective altruists have taken regarding charitable aid has significant drawbacks. Not only is its efficacy hard to determine, but the narrow focus rules out some areas which ought not be ignored. Given that I accept the first premises of EA, namely, that the capable ought to take significant steps to reduce suffering and that the actions they take for that purpose ought to be maximally effective, it now may seem unclear what kind of action a would-be effective altruist should take against this suffering. What other methods are available?

When the question of aid's effect is unclear, we may better serve those who are suffering with ascetic responses than with donation. It might be hard to control where donated money goes and what its effects are once it goes there. But if we identify the sources of harm, starving these sources of our tacit, unquestioned approval will eventually lead to system-wide change.

The causes of suffering can be difficult to identify and target for change through donation. This is in part because the Global South is created by the same economic system that produced the Global North, as Thomas Pogge describes in his article, "Responsibilities for Poverty Related Ill-Health." The global order is such that Western culture remains as dominant and influential as it was in the colonial era, and therefore, the "existing institutional order is implicated in the persistence of radical inequality [where the]

12 Brown, "Supporting the Best Charities," 242.

13 Ibid. 
better-off impose a shared institutional order on the worse-off." 14 Donation alone will not be sufficient to remedy such system-wide structural violence. Against such sources of suffering, the ascetic approach is a very much needed and too often neglected complement to donating. As Kuper says, "Given the complex interdependence and economic and political perversities that characterise our shared world, the injunction 'first, do no harm' deserves at least equal consideration." 15

Indeed, I think most effective altruists would not have a problem admitting this. When presented with the evidence that giving will not do good in one case, the effective altruist may simply redirect those potential funds toward a situation in which he or she can feel surer that it will be of benefit. Perhaps, the effective altruist will choose to donate to developing technologies to protect humanity from cataclysm due to global warming or to medical research aimed at lifesaving drugs or eradicating diseases. These are more concrete and technological sources of suffering and better suited, perhaps, to cost-effectiveness reasoning. Even so, I propose that this thinking leaves the effective altruist equation incomplete. Charitable giving is not our only opportunity to take altruistic action. Focusing solely on that misses an opportunity to expand the influence of our ethical lives.

\section{Selective Asceticism as Activism}

Asceticism has a long history, both within religion and apart from it. Religiously speaking, ascetic practice may take many forms, from vegetarianism (as it does for many Hindus), or the practice of voluntary celibacy, to the more extreme choice to live a life of seclusion (as with monks, whether Catholic or Buddhist). Ascetic attitudes even make an appearance in Plato's Phaedo, where Socrates explains the dangers of bodily pleasures and desires because of their potential to sway our values and make us believe falsehoods, ${ }^{16}$ and one can find a similar refrain in Buddhism (a faith widely known for its ascetic tendencies) in the four noble truths, the second of which identifies the origin of suffering as desire. At its most basic, however, it is the practice of deliberate self-denial with the aim of acting more ethically or acquiring virtue. ${ }^{17}$

14 Pogge, "Responsibilities for Poverty Related Ill-Health," 71.

15 Kuper, "More Than Charity," 114.

16 Ebrey, "The Asceticism of the Phaedo."

17 Besong, "Virtue and Asceticism." 
The word ascetic comes from the Greek "áskesis" meaning to exercise or train. Thus, asceticism is best understood as a discipline or practice, not merely the opposite of indulgence. Asceticism requires more than mere abstinence from some activity. It is not ascetic to refrain from eating chocolate if you never liked chocolate to begin with. Likewise, it is not ascetic to deny yourself the pleasure of a daily treat from Starbucks if your reason for doing so is simply to save up your money for a vacation next month. Asceticism is self-denial for a higher good. In religious contexts, this higher good may often be spiritually-oriented and focused on the individual believer - as in purifying one's own soul or bringing oneself closer to God. But in this paper, I hope to call attention to the "this-worldly" ethical potential of asceticism. Activists, and not just the spiritually inclined, ought to take note of the ethical potential asceticism has to offer.

Asceticism has also been met with its fair share of criticism over the centuries. Nietzsche criticised it as "hatred of the human;" 18 Bentham criticised it as a "cloak for tyranny." 19 These criticisms helped to paint it as "eccentric and uniquely religious," leading many in the post-Enlightenment to treat it with disregard. ${ }^{20}$

Yet, in more recent years, ascetic practices of one form or another have been gaining ground, as can be seen in the popularity of minimalist lifestyles, ethical veganism, and other trends. These modern incarnations may or may not be explicitly connected with the religious attitudes of the people who practice them. In addition to its resurgence in popular culture, the academic community is also waking up to the notion that asceticism may offer practical tools towards cultivating ethical behaviour (something which is supported by contemporary empirical research on self-control), ${ }^{21}$ as well as significant insight into the ethics of consumer culture and other current debates in applied ethics. ${ }^{22}$

Thus, asceticism as a method of strengthening moral character as well as an additional avenue for ethical action deserves attention from the effective altruist community. EA has traditionally focused on the "active" methods for "doing" good, such that the movement has neglected the ways in which they ought also to avoid perpetuating harm or injustice. This is a gap that a dose of asceticism would go a long way towards filling.

18 Segerdahl, "Intellectual Asceticism."

19 Koh, "Bentham on Asceticism and Tyranny."

20 Besong, "Virtue and Asceticism."

21 See Besong, "Virtue and Asceticism."

22 See Maria Antonaccio, "Asceticism and the Ethics of Consumption." 
EA's focus on money and donation amounts to a kind of tunnel vision. To give an example: within the attempts to address the global warming crisis, supporting the development of alternative fuels for cars or better electric cars is a perennial favourite. Yet, new forms of cars or fuel pale in comparison to the effects on climate change that could be produced from simply reducing the need for cars at all. Developing better, more efficient, public transport would have a much more drastic impact. Better still, we could redesign cities and transport to not rely as heavily on cars at all and adjust the culture to move away from seeing cars as basic needs (as they are often seen in the United States) and more as expensive luxuries. Individuals can propel change of this kind with investments or donations (the typical effective altruist approach), but can also practice this by abstaining from the use of cars, or planes, making the choice to take public transport or walk or bike to places they need to go, or travelling less in general.

Other ascetic methods of fighting climate change are simply becoming vegetarian or vegan since large amounts of greenhouse gases are produced through factory farming. In fact, a report by World Watch found that more than half of all greenhouse gases are produced from the animal agriculture industries. ${ }^{23}$ And a study by researchers of the University of Oxford published in 2014 in the journal Climatic Change concluded that meat-eaters are responsible for almost twice as many dietary greenhouse-gas emissions per day as vegetarians and about two and a half times as many as vegans. ${ }^{24}$ Another option for selective asceticism is to personally choose not to have children to reduce the burden of overpopulation. One need not take up every ascetic choice, but these options deserve at least as much recognition and attention as charitable donation.

I recognise this is not an entirely novel thing to say, as even Peter Singer in his book, The Most Good You Can Do, states that one of the most effective ways to decrease total suffering in the world is to stop eating meat. ${ }^{25}$ That is why I see my argument in this paper as a reemphasis rather than a revolutionary suggestion. In fact, there are already efforts being made in this regard. We just tend not to hear about them in connection with EA. Movements like conscious consumerism seek to better inform customers of the ethical impact of their purchases.

23 Goodland and Anhang, "Livestock and Climate Change."

24 Scarborough et al., "Dietary greenhouse gas."

25 Singer, Most Good, 177. 
In Waheed Houssain's article, "Is Ethical Consumerism an Impermissible Form of Vigilantism?" he gives a thorough evaluation of several types of ethical consumerism. Citizens can use their purchasing power in a variety of ways and for a variety of reasons. A conscious consumer may refrain from buying coffee produced by unfairly treated workers, or they may avoid products known to contribute to deforestation or the extinction of species in distant regions, what Houssain calls "negative ethical consumerism" because it involves refraining from buying something. ${ }^{26}$ Conscious consumers can also take action to make the world a better place by purchasing products that have been recognised as fair trade or sustainable, what Houssain would call "positive ethical consumerism." 27

If we accept that one of the engines of inequality and suffering in the world is rampant consumerism, then abstaining from consumerism in any way possible will help to effect change. Strategically abstaining from consumerism (both in the sense of abstaining from consuming goods that perpetuate harm or injustice, and in the sense of mitigating one's consumer appetites more generally) can attack the roots of these problems, especially when combined with advocacy and public pressure on companies that use unfair labour practices, cause deforestation, use child labour, and more.

This type of activism would be a kind of negative ethical consumerism aimed at creating systemic change, what Houssain dubs a kind of "protolegislative" social change ethical consumerism (SCEC). ${ }^{28}$ The use of such strategies "essentially creates arenas of informal democratic self-governance that operate below the level of formal democratic politics." ${ }^{29}$ Houssain elaborates on the benefits of ethical consumer action:

"In a large, complex, and technologically sophisticated society, citizens cannot make all of the rules necessary to direct market activity to desirable outcomes through the formal legislative and regulatory process. As things stand, when issues do not make it on to the formal democratic agenda, they are left to the unregulated market. But with proto-legislative SCEC, citizens can address issues that need attention but do not get on the formal agenda through informal self-regulation in secondary arenas." 30

26 Houssain, "Ethical Consumerism Impermissible Form of Vigilantism?” 113.

27 Ibid.

28 Ibid.

29 Ibid, 132.

30 Ibid. 
This type of activism can have many benefits, like helping to bring attention to issues that are "perpetually secondary" (like deforestation) and fostering a "legislative will" where citizens can organise themselves on issues that languish in formal politics. ${ }^{31} \mathrm{He}$ continues:

"A closely related benefit is increased governability. Corporations are powerful social actors, with privileged access to political authorities, and they often oppose laws that would protect the rights and interests of weaker players in the market. But the orientation of corporations is closely connected with the orientation of consumers. If consumers are narrowly interested in price and quality, without regard for how a firm delivers these goods, then firms stand to profit from reduced protections for weaker players. But if consumers are sensitive to whether a firm respects the rights and interests of others, there will be less profit to be made in taking advantage of weaker players, and this in turn will make firms less hostile to regulatory efforts to protect these players." 32

A final benefit of proto-legislative SCEC is that it can "expand the sphere of citizen engagement." 33 Someone who does not identify with any political party or have general views about economic policy may still find it quite natural to express his or her wishes for the common good through everyday purchases. Websites like EthicalConsumer.org provide an abundance of articles and data regarding the ethical influence of consumer choices with the aim of providing consumers the tools they need to make such decisions. Such sources of information may lead interested consumers to eventually take more active roles in democratic politics. ${ }^{34}$

Though the kind of proto-legislative SCEC Houssain describes encompasses both positive and negative forms of ethical consumerism, I have chosen to focus on the negative form for this article because it is often underexplored and underutilised. Lumping selective asceticism as one subcategory of ethical consumerism is misleading since by its nature it is anti-consumerism. Thus, strategies like this can benefit from having their own name. Asceticism as activism aimed at creating systemic social change should be seen as a form of EA in its own right and deserves attention as such.

To be clear, I am not arguing that charitable donation is never a suitable option for altruistic action. There are some cases where it can be both appropriate and effective. For instance, in combating deaths due to malaria,

31 Ibid.

32 Ibid, 133.

33 Ibid.

34 Ibid. 
donating to researching and distributing treatment and to organisations that help prevent its spread may help to ultimately consign malaria to the dustbin of history. Yet, the zeal with which EA has approached charitable giving is likely inflated and inappropriate. Donation can be one tool among many in the effective altruist's toolbox, but we should be very careful and attentive to the situations in which it is applied and willing to recognise its limits.

I am also not advocating a life of complete disengagement from the world. The kind of asceticism I am proposing is selective, targeted to remove support from the unjust systems in the world that profit from the exploitation of others and the planet. Asceticism is not the only way to respond to these issues, but it is a tool that is too often neglected.

\section{Against Earning to Give}

As we have established, effective altruists are interested in (1) helping others and (2) doing so effectively. The earning to give sub-trend accepts that the best way to do so is donation to effective charities, and seeks to maximise the power to do so by seeking careers with the most financial potential. But as I have demonstrated, we have serious reason to question the faith effective altruists have placed in the benefits of donation - at least in some contexts. As we shall see next, there is reason to question the "earning" side of "earning to give" as well.

Even if we give away massive sums to good causes (and even if these causes are effective), if we are not conscious of the kinds of systems to which we are giving our life and our time, we may be missing important elements of the moral picture. To give a hypothetical comparison, if you make a living by slaughtering animals, but donate all your earnings above subsistence level to vegan causes ... are you doing the most good you can?

Blanket approval for any job that allows you wealth and status is dangerous, no matter how altruistically one applies the wealth and status once achieved. Indeed, the effective altruist movement has strongly emphasised this very point in more recent years (an article on 80,000 hours' website by Benjamin Todd, "Is it Ever Okay to Take a Harmful Job in Order to Do More Good? An In-Depth Analysis," was published mere months after the publication of my original paper this chapter is based upon). Careers are not all morally neutral activities. Indeed, some careers may be neither helpful nor harmful to the world, but to an effective altruist interested in maximising one's positive influence, the ethical potential of all the hours we 
spend working should not be ignored. This would seem to place the preference back on the jobs we usually think of as morally admirable - working directly for aid agencies, becoming an activist or advocate for the worse off, becoming a doctor, etc. There is an extra reason to be wary of the earning to give. High-paying jobs and high-status jobs often are high-paying and high-status because they are key positions in the very economic system that maintain the unequal status quo. As I have already established, this system itself is implicated in the structural violence that causes so much harm in the first place.

Ascetic strategies, on the other hand, like refusing to participate in forms of consumerism which perpetuate the divide between the Global North and Global South or giving up meat to reduce both greenhouse gases and prevent animal suffering can potentially transform society so that these causes of suffering eventually cease to exist. Asceticism is a form of activism in this way and can be a form of public protest and can help to establish and promote alternative ways of living. Donating to charities that can help children in impoverished communities is only half the solution; we must also stop buying the products that come from their exploitation. By recognising these other strategies, we may be able to enlist more people in the fight to reduce suffering in the world.

Some effective altruists will defend earning to give by arguing that if a person rejects a high-paying job in banking or finance on ethical grounds, this does nothing to prevent someone else from taking that job. ${ }^{35}$ Further, the person who does take the job may be less likely to donate what the effective altruist would, and less likely to advocate for reform from within the system. To this, I will concede some ground. In the situation where an altruistic individual has the talent and opportunity, I would not automatically condemn the acceptance of such a career choice. Yet, I would also be keen to point out that donating all the money earned from such a job to effective charities does not go far enough, since it is insufficient to effect lasting systemic change. It is also highly risky, given the psychological effects of peer pressure and life-style creep one is likely to be exposed to within certain career circles.

The emphasis for the truly effective altruist interested in earning to give needs to be on the creation of systemic institutional change. Thus, I would argue that, advocacy for reform from within should be the primary target when making such a career choice for such individuals. If such advocacy is 
effective, then the negative effects of the career choice would vanish, and so would my objections.

Yet, I think it is worth pointing out that careers come with cultures and social pressures of their own. Our moral motivations are often influenced by our social groups, so we should cultivate those groups carefully. It would be arrogant to assume that we are immune to the potentially negative effects of peer pressure just because we go in with good intentions. Changing the system from within is an admirable goal but much harder to accomplish than many people may assume. Individuals who have an interest in the path of earning to give should undertake it with due consideration.

\section{Addressing the "Overdemandingness" Objection}

EA may indeed have an undue emphasis on donation and a potentially counter-productive love affair with earning to give. However, its central claims remain unchallenged, even when these two expressions of the movement fall apart. One common objection levied at the very heart of EA is the worry that it is overly demanding. Even the ascetic strategies I am proposing are open to this accusation. Being informed enough about the wide-ranging effects of our everyday purchases, the ethical influence of our jobs upon the world, and every choice we make regarding where to place our money and our time is a steep task. Some worry that such a high standard of ethical behaviour would actually reduce the value of our lives.

This fear is echoed by Kuper in his objection to Peter Singer. Kuper fears that Singer's suggestions will prompt any of us who wish to lead ethical lives to "give up any job that doesn't directly or maximally involve saving lives." ${ }^{6}$ Kuper argues, "there are many values other than survival: Can it be morally required to give up vital sources of meaning, such as the work we do, the social commitments we have, and the knowledge and excellences we pursue?"37

The objection stems, perhaps, from the effective altruist slogan, which is the title of one of Peter Singer's recent books, The Most Good You Can Do. This is the battle cry of the effective altruist. Worries of overdemandingness arise from the first half of the phrase. If one's aim is to do the most good possible, there seems to be no indication of a natural stopping point. Indeed, there may always be more good that one can do, and more effective ways to go about doing it waiting to be discovered.

36 Kuper, "More Than Charity," 110.

37 Ibid. 
Yet, the real worry about overdemandingness is not about whether we can or will ever discover a single perfect recipe for the "most good." The concern is rather that EA is too burdensome of an ethical standard. If one must maximise the ethical potential of one's actions, then all of life will quickly be subsumed into that project - leaving no time for any other activities or values, or any of the things many of us consider natural, normal, and quintessentially human, like spending time relaxing with family and friends.

This criticism hinges largely on the idea that EA presents itself as a moral obligation - something which many effective altruists have explicitly denied. ${ }^{38}$ Rather than a moral obligation to maximise the good we do (as in some forms of act utilitarianism), EA merely claims that maximizing the good is a valuable goal. ${ }^{39}$ With the obligation removed, the overdemandingness objection loses most of its teeth.

To defang the objection further, I will point out that there are many activities and obligations we accept in life that are similarly demanding. For example, it is widely accepted that we ought to maintain our health. It may not be seen as a moral obligation, but since health is something most of us intuitively value, we accept the idea that the pursuit of health is worth some effort. What is more, we accept that health is worth the effort to pursue, even knowing that it is impossible to achieve and sustain a perfect state of health ad infinitum (given the fact that we are all mortal).

Most of us do not see maintaining our health as overly demanding, and we know that despite our best efforts to stay healthy, we will still inevitably fall sick and even die at some point. We do not see this as somehow undermining the value of trying to be as healthy as we can while we still live. This is because it is so clearly vital to the other things we care about in our lives. Everything else we enjoy, we enjoy longer and more fully when we are healthy. I would argue the same for the kind of ethical attentiveness that effective altruists adopt.

Additionally, the accusation of "overdemandingness" only serves as criticism if the ultimate goal of the actions demanded fails to measure up - or to put it more simply: it is only a problem if the juice is not worth the squeeze. Many activities are extremely ambitious or demanding, including some religious practices, as is the case with some monks who choose to live lives of seclusion in order to pursue greater devotion to God. Even leisure activities and hobbies, like mountain climbing or body building, when

38 MacAskill, Mogensen, and Ord, "Giving Isn't Demanding."

39 Ibid. 
practiced with sufficient intensity, place severe demands on the individual that others might find life-deranging (exposing oneself to the elements or subsisting on nought but broccoli and egg whites is not for everyone). The fact that these activities are taxing, or come with serious opportunity costs, etc., is not a problem for those people sufficiently motivated by the goal.

Likewise, the selective asceticism I am advocating here is able to preserve the kinds of things we commonly hold dear in life. We can still enjoy all manner of pursuits, like art, or music, writing novels, etc., as long as we care enough to ensure these activities do not harm others. We need not perceive these activities as "time wasted" that we could have spent helping others or earning more in order to give more away.

Just as one can select between worthy causes to which to donate, one can also select between various ascetic practices. For some of us, being vegan could be too taxing on our personal health, and for others to abstain from having children would bring severe emotional pain. We need not all live the life of a childless bicycling vegan. Yet, we can and should think strategically about our "negative" ethical options. For those of us who would not suffer from such forms of asceticism, it can be a powerful tool to effect positive change in the world. For those of us who would suffer, there are still a host of other opportunities to make a difference, and these tend to be the ones we already know about - volunteering, donating to charities, etc.

As Anthony Skelton observes in his article, "The Ethical Principles of Effective Altruism," what truly unites the effective altruist community is a common perspective characterised by:

"First, a heightened receptivity to evidence and facts in thinking about how best to
achieve philanthropic ends. Second, effective altruists have, perhaps unwittingly, hit
on a sensible way of ... reconciling prudence and beneficence; they appear to have
stumbled on what psychologists have been reporting, that above a certain threshold
increases in income and wealth produce fewer and less long-lasting increases in
life satisfaction. Effective altruists have discovered that for happiness, for life satis-
faction, one needs much less materially than our cultural norms suggest." 40 In reality, the effective altruist life is not a life so burdened as to be devoid of any pleasure. In fact, altruism and asceticism go hand in hand to produce more happiness for effective altruists themselves, as well as helping to alleviate suffering for others in the world.

40 Skelton, "Ethical Principles of Effective Altruism," 144. 


\section{Conclusion}

EA gets many things right: we have a duty to help others, no matter how distant, and those in the Global North have the privileged position in that their affluence can make a significant impact on those far away with little cost to themselves. It is good to bring attention to the moral potential of money, but it is short-sighted to think that some of the problems of the world can be solved merely by donating. Because of the emphasis on "effectiveness," it should be natural for EA to seek solutions that prevent harm rather than just ameliorate it after the fact, which is why it is strange that ascetic strategies are often so neglected.

EA as a movement has developed an unhealthy obsession with cost-effectiveness analysis, which has led them away from what should be their core mission. It has left the movement unable to spot effective solutions to systemic sources of suffering, which often have political dimensions that are hard to measure with the quantitative approaches the movement favours. However, none of these flaws is fatal. Donating to effective charities has only ever been a part of the broader cause, and it is time to give more attention to the other approaches available. The first rule of getting out of a hole is to stop digging. This is what the ascetic's approach to EA seeks to reemphasise.

Both a narrow focus on monetary donation and extreme asceticism to the point of complete disengagement from society fail to effect positive change in the world in a maximal way. Thus, I am arguing for what I see as the middle way, where attention is devoted equally to the effects our money can have on the world and the nature of the activities we devote our time to. In doing that, we have the opportunity to create a more just and fairer global order and reduce the negative impact of structural violence.

This places a burden on us to be informed of the far-reaching consequences both of our actions and of our inactions. The most effective altruistic life will be demanding but not incongruous with our other values. We must seek opportunities to help others, and we must stop contributing to systems that harm them. This balancing act requires a moral attentiveness that can be strengthened with practice. Through a balance of selective asceticism and cost-effective charitable donations, we each have huge and mostly untapped potential to transform our world. We do not need to think our actions will create a perfect world in order for them to be worth doing. Making the world a better place should not be seen as a burdensome addition to our lives but rather an enriching dimension. Looking after our 
positive impact on the world is like looking after our own health. It is negative and counter-productive when we become obsessive about it, but, for most of us, it is important enough to devote daily activity toward, through both positive actions and selective abstinence. ${ }^{41}$

\section{References}

Antonaccio, Maria. "Asceticism and the Ethics of Consumption." Journal of the Society of Christian Ethics 26, no. 1 (2006): 79-96.

Besong, Brian. "Virtue and Asceticism." Philosophy 94, no. 1 (2019):115138. https://doi.org/10.1017/S0031819118000347.

Brown, Steven G. "Supporting the Best Charities is Harder than it Seems." Journal of Global Ethics 12, no. 2 (2016): 240-244. https://doi.org/10.10 80/17449626.2016.1205118.

Clough, Emily. "Effective Altruism's Political Blind Spot." Boston Review, 14 Jul, 2015.

Ebrey, David. "The Asceticism of the Phaedo: Pleasure, Purification, and the Soul's Proper Activity." Archiv für Geschichte der Philosophie 99, no. 1 (2017): 1-30. https://doi.org/10.1515/agph-2017-0001.

Freiberger, Oliver. Asceticism and its Critics: Historical Accounts and Comparative Perspectives. Oxford, New York: Oxford University Press, 2006.

Gabriel, Iason. "Effective Altruism and its Critics." Journal of Applied Philosophy 34, no. 4 (2016). https://doi.org/10.1111/japp.12176.

Goodland, Robert and Jeff Anhang. "Livestock and Climate Change." World Watch, November/December (2009).

Horton, Keith. "Aid Agencies: The Epistemic Question." Journal of Applied Philosophy 28, no. 1 (2010): 29-43. https://doi.org/10.1111/j.1468-593 0.2010.00504.x.

Houssain, Waheed. "Is Ethical Consumerism an Impermissible Form of Vigilantism?" Philosophy and Public Affairs 40, no. 2 (2012): 111-143. https://doi.org/10.1111/j.1088-4963.2012.01218.x.

Koh, Tsin Yen. "Bentham on Asceticism and Tyranny." History of European Ideas 45, no. 1 (2019):1-14. https://doi.org/10.1080/01916599.2018.15 14643.

41 I would like to include a special thanks to the International Society for Utilitarian Studies for letting me present this paper at their conference at Lille Catholic University in July of 2016. I would like to thank Peter Singer for giving me feedback on my paper at the conference and thank Thomas Ferretti for his thoughtful notes on a previous draft. 
Kuper, Andrew. "More Than Charity: Cosmopolitan Alternatives to the "Singer Solution"." Ethics and International Affairs 16, no. 1 (2002): 107-120. https://doi.org/10.1111/j.1747-7093.2002tb.00378.x.

MacAskill, William, Andreas Mogensen, and Toby Ord. "Giving Isn't Demanding." In The Ethics of Giving: Philosophers' Perspectives on Philanthropy. Oxford: Oxford University Press, 2018. https://doi.org/10.1093/o so/9780190648879.003.0007.

MacAskill, William. "Replaceability, Career Choice, and Making a Difference." Ethical Theory and Moral Practice 17, no. 2 (2014): 269-283. https://doi.org/10.1007/s10677-013-9433-4.

Pogge, Thomas. "Responsibilities for Poverty Related Ill-Health.” Ethics \& International Affairs 16, no. 2 (2002): 71-79. https://doi.org/10.1111/j.1 747-7093.2002.tb00398.x.

Scarborough, Peter, Paul N. Appleby, Anja Mizdrak, et al. "Dietary greenhouse gas emissions of meat-eaters, fish-eaters, vegetarian and vegans in the UK." Climatic Change 125, no. 2 (2014): 179-192. https://doi.org/1 0.1007/s10584-014-1169-1.

Segerdahl, Pär. "Intellectual Asceticism and Hatred of the Human, the Animal and the Material." Nordic Wittgenstein Review 7, no. 1 (2018): 43-58. https://doi.org/10.15845/nwr.v7i1.3494.

Singer, Peter. The Most Good You Can Do: How Effective Altruism Is Changing Ideas About Living Ethically. New Haven: Yale University Press, 2015.

Skelton, Anthony. "The Ethical Principles of Effective Altruism." Journal of Global Ethics 12, no. 2, (2016): 137-146. https://doi.org/10.1080/17449 626.2016.1193552.

Todd, Benjamin. "Is it Ever Okay to Take a Harmful Job in Order to Do More Good? An In-Depth Analysis." 80,000 Hours. June 2017. https://8 0000hours.org/articles/harmful-career/.

Todd, Benjamin. "Misconceptions About Effective Altruism." 80,000 Hours. 7 Aug 2020. https://80000hours.org/2020/08/misconception s-effective-altruism/. 